\title{
$7 \quad$ Attitudes and Ideologies in Language Revitalisation
}

\author{
Nicole Dołowy-Rybińska and Michael Hornsby
}

\section{Introduction}

While there are many reasons that we might initially have for wanting to preserve a language, as detailed in the earlier chapters of this volume, people may also have underlying assumptions about the processes of language revitalisation that go unexpressed. These are generally known as language ideologies, which we discuss in this chapter. These ideologies are often expressed and materialise in the form of language attitudes. Below, we show how language attitudes can affect attempts to save an endangered language; it is difficult to plan any positive language revitalisation without ensuring positive attitudes towards the minority languages (people must actually want to use the language if revitalisation is to be successful).

One of the most important tasks, then, for any language revitaliser is to listen to the various attitudes expressed within the community towards their endangered language and to try to work out what ideologies lie behind these attitudes. Such attitudes will be varied, possibly contradictory and nuanced, of course, so we need to be extremely sensitive in dealing with them. Without doing so, it is unlikely that language revitalisation will be successful. It is also very important that attitudes held by the majority language community are taken into account. Majority views affect minority language speakers, as they can influence the community and discourage actual and potential speakers from using the language. Challenging negative impressions held by majority language speakers is therefore an equally important task for language planners. In this chapter, we explore some of the more prevalent ideologies and attitudes found in minority language communities. In doing so, we aim to raise awareness of these issues amongst language planners and minority language activists, helping them to revitalise their local endangered language.

\section{Language Ideologies}

Pick up any textbook concerned with minority language sociolinguistics, or start reading an article which discusses the situation of any given minority 
language and, in all likelihood, it will not be long before the concept of 'language ideology' is encountered. Therefore, we start this chapter with a consideration of the term 'ideology' as it relates to languages and, in particular, to minority languages. There have been many attempts to define what a language ideology is, and some of them are quite complex. This complexity can be confusing for activists engaged in revitalisation. At the opposite end of the scale, however, some writers have used the term without any careful consideration of what they actually mean when they write 'ideology', sometimes using it as an alternative for 'attitude'. We consider that there is a significant distinction between the two terms and that, for minority language activists working on preserving their languages for the future, an understanding of the difference is very important in helping them plan their revitalisation strategies.

For our purposes here, we understand language ideologies as those beliefs, feelings, and assumptions about language that are socially shared and which attempt to make sense of different forms of the language (dialects in relation to a standard language, minority languages in relation to majority languages, youth speak in relation to older generations' way of talking, etc.) and their place in society. Most importantly, ideologies of language represent assumptions about particular linguistic forms and what they say about the people who use them. For example, we often attribute certain social values to a speaker who prefers to use one language over another, one who uses slang or swear words regularly, or who speaks with a particular accent. In this sense, language ideologies are closely connected to language stereotypes, where languages (and their speakers) can be attributed as having certain characteristics, even when these characteristics cannot be objectively demonstrated. For example, claiming that language A sounds more beautiful than language B, or that someone 'hates' the sound of a particular language, are both claims rooted in language ideology, which can then emerge through explicit statements which we call 'language attitudes'. (See below for the difference between language ideologies and attitudes.)

This idea is best demonstrated by considering a common language ideology that can be found in many societies: the so-called standard language ideology. The standard language ideology refers to the belief that a particular form of language, usually the variety that is used by the most powerful group in society, is superior in some way to other varieties of the language. The standard variety of a language is often based on written forms, which have been unified in some manner and are typically acquired after many years of formal education. Even though this variety may actually be spoken by only a minority of the population, the vast majority of speakers of the language recognise it as somehow 'superior' and 'prestigious'. Even in the case of many European national languages, which have only been standardised recently (e.g. the Finnish or Czech languages), 
they gain the status of the language that should be used and protected by the state. Ability in this standard language justifies the privileged societal positions of its speakers, whereas a lack of ability in it often results in exclusion from such positions. Thus, a standard language ideology can make this situation seem fair and equitable - both to those who benefit from it and to those who are disadvantaged by it.

\section{Differences between Ideologies and Attitudes}

It can thus be seen that ideologies operate at a subconscious level and that people may not be aware of their existence. However, ideologies can become apparent through people's attitudes towards a given language or language variety. Language attitudes are the explicit evaluations of particular languages and language varieties, expressed by people as opinions and beliefs and, more negatively, as prejudices. They influence people's thought processes and their specific language choices. We refer to the Irish example here. In the Republic of Ireland, the Irish language is viewed favourably by over 60 per cent of the population, who agreed with the statement: 'Without Irish, Ireland would lose its identity as a separate culture'. ${ }^{1}$ However, according to the Irish Times, quoting the 2016 census figures, the percentage of people using Irish as a daily language in the Gaeltacht (the officially designated Irish-speaking areas) has fallen by 11 per cent. Outside of the Gaeltacht, where just over 90,000 people live (2.1 per cent of the total Irish population), some 53,000 people in the rest of the Republic use Irish as a daily language (1 per cent of the total population). ${ }^{2}$ Given that there is a generally positive view of the language by most adults in the Republic, we might expect more people to be using the language for identity and cultural reasons. However, it would appear that being favourably disposed to a language does not translate into actual use. In thinking about these results, it is worth questioning the nature of the survey itself - if the questions had embraced a more complete spectrum of attitudes (including, for example, the perceived usefulness of the language, and its economic worth) then the results might have looked very different.

\section{Common Language Ideologies in Minority Settings}

Researchers have noted a number of ideologies that are regularly found in minority speech communities. The linguistic anthropologist Kathryn Woolard $^{3}$ has identified two of the most important ones as being:

1 Economic and Social Research Institute (2015). $\quad{ }^{2}$ Irish Times (2017).

3 See K. A. Woolard, 'Language and identity choice in Catalonia: The interplay of contrasting ideologies of linguistic authority', Workshop on Language Ideology and Change in Multilingual 
The ideology of authenticity, which 'links the value of a language to its relationship with a particular community'. To be considered authentic, speakers must recognise the speech variety as being 'from somewhere', and with a particular local quality. Thus, in many minority language situations, one of the markers of a good speaker is the ability to use a particular dialect, or to speak using a recognisably local accent. If such markers are absent, a linguistic variety may be seen by the community to lack value. In revitalisation contexts, authenticity can prove to be a problem when new speakers acquire the language. These learners may not see themselves as sounding sufficiently natural compared with native speakers. In turn, native speakers may 'close ranks', and exert a sort of ownership over speaker identity, privileging their position as 'authentic' speakers. This state of affairs can lead to frustration from learners, sometimes deterring them from using the language altogether.

The ideology of anonymity, which holds that a language is a neutral means of communication equally available to all users. This view is universalist in nature and seeks to include all members of a speech community, however they may have acquired the language. Anonymity is the opposite of authenticity, in that membership is not evaluated by how 'local' a speaker sounds, but more on how well or how often they use the language. This ideology is closely related to the ideology of standard language, in that some users of a particular language actively avoid using dialectal or local forms and instead use the standard variety. In this way, the ideology of anonymity promotes a shift away from an 'authentic' or 'native speaker' identity and towards a 'civic' identity that regards the minority language as a resource for constructing a cosmopolitan, modernised identity.

These two ideologies can lead to tension in minority language situations. For example, the spread of Irish outside of the traditional Irish-speaking strongholds and into areas previously dominated by English has complicated traditional ideologies of authenticity. Most commonly, native speakers of Irish were from very rural areas and their language reflected this, with highly localised dialects and a very developed vocabulary in the traditional occupations of the west of Ireland, such as fishing and farming. As a result, this group was put forward as 'ideal' (or idealised) speakers; when Irish was being revitalised in the early years of the state, language planners gave traditional native speech communities a high prestige status based on their perceived authenticity. This view has remained a deeply rooted language ideology. Yet the rise of a more educated and urban group

Communities, UC Diego, 2005, https://escholarship.org/uc/item/47n938cp; and K. A. Woolard, Singular and Plural: Ideologies of Linguistic Authority in 21st Century Catalonia (Oxford: Oxford University Press, 2016). 
of speakers in places such as Dublin, Galway, and Cork has resulted in a series of tensions. While the ideology of authenticity positions traditional native speakers as the 'owners' of the language, this view has been rejected by language users outside of the traditional Irish-speaking areas, who perceive the language as a symbol of a newly constructed national identity.

Very often connected to the concept of authenticity are ideas about language ownership. In some people's view, a language is 'owned' by its native speakers. This means that their beliefs regarding the 'correct' forms of language are seen as authoritative and they have the final say on what constitutes 'good' language and a 'good' accent, etc. Accordingly, areas where the language is traditionally spoken are often perceived as repositories for the language where people can experience it in its 'natural' environment and access an authentic language-learning experience to become 'real' speakers. However this commodification (or the objectification) of the language can create tensions between those who were seen to produce the commodity (i.e. native speakers) and those who wished to consume it (i.e. learners); while the ideology of authenticity positions traditional native speakers as language 'owners', learners of the language often contest this on the grounds that they too have a right to the language.

Language ideologies based on authenticity can also relate to the perceived usefulness of a language. For a language to be perceived as authentically useful, it very often needs to have a pervasive presence in society - it needs to be seen and heard everywhere - and in that sense, normalised. A normalised (majority) language is seen as the common sense, default option in day-today life and official interactions. In a sense, it is the common property of all community members, including those members who also speak another language. The normalised language thus comes to be seen as the most appropriate and most useful means of communication in society. In this situation, transgressing community norms by using a minority language in public may be challenged by non-speakers, who see such behaviour as 'rude' or inappropriate. These ideologies can filter through to the minority community where they are adopted, often subconsciously, by speakers who then choose to use their minority language privately, out of the public domain. In Brittany, for example, it has been noted that when older Breton speakers are out shopping in the supermarket they tend to talk in Breton quietly to each other and will switch to French when a stranger walks past them, switching back to Breton only once they are out of earshot.

The challenge facing many minority language activists is to deal with these issues and work with speakers to help them overcome ideological barriers in using the language. If this does not happen, then it may add to the pressure on minority language speakers to switch to the majority language in all situations, including intergenerational transmission to the younger 
generations. In such cases a sense of shame can develop, which is often accompanied by a feeling of uselessness as far as the minority language is concerned. The majority language comes to be seen as the language of advancement and betterment, and as the way to secure a more prestigious job and the language to raise children in. Linking minority language use with a sense of purpose, a sense of pride, and above all an essential part of the group's identity, are key to securing a future for the endangered language. Furthermore, and perhaps just as importantly, activists must raise awareness amongst the majority population and attempt to involve them as allies in the preservation and revitalisation of the minority language. There is no magic formula which can be applied universally in all minority language situations and one of the main tasks of activists and concerned speakers in the minority language community is to work out just exactly how to do this, given local conditions and local language ideologies.

The anthropologist Kathryn Woolard has dissected the term 'ideology' into four strands: (1) ideology as a mental phenomenon - the domain of the ideational and conceptual; (2) ideology as the foundation of metapragmatics (the discourse of the effects and conditions of language use); (3) ideology as linked to positions of power through discursive practices - the struggle to acquire or maintain power; and (4) ideology as distortion, maintaining the relations of power by disguising or legitimating those relations. We offer some practical ways for language revitalisers to explore these four strands in the concluding section of this chapter.

\section{Language Attitudes}

Everybody has beliefs and feelings about languages based on the way that society perceives them and the stereotypes associated with them. They are socialised through various agents, including teachers, peers, family, and the media. Furthermore they tend to relate to two aspects of the community: status and solidarity. Status refers to both the personal characteristics of those who use the language (e.g. if language speakers are perceived as educated and intelligent) and the external image the community or the language itself has (e.g. if it is not perceived as a 'real' language but as a dialect of another language). Solidarity refers to the extent that a specific language or variety is associated with group membership and belonging to the community. Evaluations made regarding status and solidarity may be positive or negative, and language attitudes can be seen in people's reactions to different language forms, practices, and varieties. A speaker's accent, the vocabulary used, the particular language chosen (especially in the situation of unequal bilingualism, i.e. when minority community 
members are bilingual in both the minority and majority languages while the rest of population inhabiting a given territory speak only the dominant language and do not consider knowledge of the minority language as important) all give clues about who the speaker is, what their personality is like, their social status, and even their appearance. This evaluation is based on the stereotypes and language ideologies that operate in society and are learned from early childhood. This image of minority language speakers and their language influence how people react to them and how they act towards them. In this way, language attitudes may be seen as a bridge between ideologies and behaviours. Furthermore, because they directly influence language choices, they are key elements of any revitalisation program.

As we have shown, language attitudes are the opinions, ideas, and prejudices that people have towards a language or language variety. For example, some people may think that a language that does not have a written form is not a real language. Others may associate a specific accent with being uneducated, while some people feel shame when using their language in a public place, or feel attacked when other people speak a minority language in their presence. In contrast, some people may feel proud of their language and perceive it as more beautiful than other languages. They may, as in the case of Basque, claim that their language is the oldest in the world, highlighting the uniqueness of their language to create more positive attitudes towards it and secure its future. As we can see, language attitudes are based on language ideologies that are often covert and have been internalised by individuals within a community so that they are perceived as natural.

Language attitudes should be identified and addressed as a core element of language revitalisation. When a community has strong negative language prejudices regarding their way of speaking, their feelings about using the language in different domains are also negative. In this situation, reversing language shift may be very difficult or impossible. In contrast, positive attitudes towards a minority language may inspire activists and community members to act against language shift. Just like language ideologies, language attitudes can also be changed. However, this is a long and difficult process that should be planned at many different levels, including changing negative attitudes that may exist in the minority speech community, and those possessed by the dominant community. The work should target both bottom-up language policy and state language recognition. Through some examples, we will explore some different types of language attitudes and consider how it might be possible to change them. 


\section{Negative Attitudes Resulting in Negative Language Practices}

Negative language attitudes in the dominant society can have serious consequences for the minoritised speech community, leading to prejudice and discrimination. Negative language attitudes that have been internalised by the group are the most difficult to change. These attitudes are the result of long-term language trauma related to discrimination and the unfair and humiliating treatment of people because of the language they use. Language ideologies and their related language attitudes can be very powerful and can become an instrument of domination. For example, the belief that one way of speaking is less prestigious than another can run very deep. This is particularly true when different methods for oppressing the language have been used, such as banning the language, negative media discourse, physical punishment for using the language, and psychological abuse. In these cases, negative attitudes can be instilled in people's minds so that they start to treat them as an objective truth. People who are linguistically discriminated against often perceive their language as worthless and a source of shame, seeing it as the cause of their own suffering and misfortune. Wanting a better life for themselves that is free from humiliation and deprivation, they often feel compelled to abandon the language and do not transmit it to their children.

Linguistic discrimination is often the reason why intergenerational transmission of a language breaks down. An example of this is the Breton language in France. The language trauma there was so strong after the Second World War that the number of speakers decreased from $1,100,000$ to 200,000 over the course of the twentieth century. This was the result of a combination of several factors, including strong language ideologies associating Breton with the language of uneducated people and poverty, which led people to feel shame when using it in public; linguistic discrimination of Breton speakers at the political and social levels (e.g. social exclusion and hindered access to the labour market); direct persecution of Breton speakers at schools (e.g. corporal punishment of children, or the symbolical punishment of children caught while speaking Breton marked by an object hung around their neck until a stigmatised child caught another one speaking Breton) and the persecution of speakers in other spheres (e.g. Breton soldiers' traumatic experiences during the First World War when - because they did not understand orders issued in French and were not able to contest them - they became 'cannon fodder', with the number of Breton deaths being significantly above the French average).

The effects of this type of internalised language trauma can be seen in the following statement: 'I spoke the language $\mathrm{X}$ and it caused only problems. I want to forget this language and I do not want my children to use it'. When 
language trauma results in language shift, revitalisation projects must occur alongside efforts to end discrimination and create positive language attitudes, both within the speech community and outside of it. It is often the case that the generation who suffered because of direct language discrimination and did not transmit the language (thus making them the last 'native' speakers of a language) are not willing to participate in language revitalisation efforts. However, they should not be left behind. This situation can often cause a sense of guilt for not having transmitted the language. Sometimes this generation can downplay or even deny that linguistic discrimination against them took place. It should be stressed that language trauma can be inherited by the next generation, making any community work sensitive. Efforts to create language prestige should be linked to top-down language policy, recognition of the language, as well as bottom-up activities aimed at showing people that their language is in no way worse than the official one. Language ideologies and related language attitudes should be deconstructed in order to make people aware that they are only social constructs created to deprive them.

\section{Positive Language Practices in the Face of Negative Attitudes}

Negative language attitudes and language discrimination may lead to different behaviours in different speech communities. These can be understood as the adaptation strategies of a community and its individuals. These strategies include decisions about what language to use and what group to identify with. In many cases, to avoid discrimination, people abandon their language and choose the dominant one instead so that they are not disadvantaged socially, culturally, or politically. However, social and linguistic inequality and discrimination may also lead people to assert their right to use their language. This is illustrated by the attitude: 'My language is oppressed so I have to do my best to protect it'.

Many endangered language activists are motivated to protect their language, community, and freedom, by grievances and the rejection of discrimination and persecution. Language activists take on responsibility for the language and the future of the speech community, undertaking different activities aimed at maintaining the language. An important part of these activities is to change the negative language attitudes already internalised by many community members. This can happen at different levels, including: discursive, where the language is described as equal to the dominant one; behavioural, where the endangered language is introduced to public spheres where it was previously forbidden or perceived as inappropriate; militant, where the language is promoted through direct and indirect acts of social rebellion; and political, where official recognition of the language is 
campaigned for. These activities may be undertaken at both the public and the private level and act as personal 'testimonies' for those people fighting to save the language. Through all these activities, and by reversing the negative image of a language, it is possible to gradually change language attitudes.

\section{Negative Language Practices despite the Existence of Positive Attitudes}

Changing the language attitudes of a speech community is a multilayered process and does not necessarily lead directly to reversing language shift. In other words, negative language ideologies are sometimes so deeply internalised that even when erased on the conscious level, they still resonate in the actual language practices of people. This attitude may be represented by the statement: 'I support language revitalisation but I will not learn this language/I will not send my child to the bilingual school'. This situation has negative consequences for revitalisation efforts.

To illustrate this, let us take the example of the Kashubian language in Poland. This language belongs to the same language family as the Polish language and, for political reasons, was treated as a 'dialect' of the Polish language (a language ideology). Its prestige was low: it was not recognised by the state and its speakers were associated with rural life, and a lack of education and job opportunities. Moreover, after the Second World War, in the Polish People's Republic, based on the concept of building a unified monocultural and monolingual - society, Kashubian speakers suffered language discrimination and many of them had traumatic experiences at schools with regard to their language. Although efforts to maintain the Kashubian language began two decades ago and it is now recognised as a regional language of Poland, negative attitudes and ideologies still influence people's language practices. For many years, there has been no social acceptance for establishing schools with Kashubian as the language of instruction, the argument being that those children would experience language problems in the future. These attitudes persist today. Gradually, with numerous efforts undertaken at different levels and thanks to language activists who have gradually broken down these mental barriers, the effects of language trauma and language ideologies are being eliminated.

\section{Positive Language Attitudes and Positive Language Practices}

The speech community may also have positive attitudes towards their language and assert that it should be protected and used by people in all domains. In the context of minoritised languages, these positive attitudes 
may result from: speakers' resistance to discrimination ('I am prevented from speaking my language but I do it anyway because I want it to survive'); strong positive ideologies related to the language ('I speak my language and I am proud of doing so'); or successful revitalisation efforts ('I have learned the language of my community and I speak it to my partner and children'). When there are numerous people with such language attitudes, there is hope for the future of a language. In the last example given, we see a person who did not acquire the language through conventional family transmission but who learnt it at schools, on a special course, or through contacts with the speech community. Moreover, this person has enough motivation to make it the language of everyday life. Finally they have decided to use the language with her or his family despite the fact that it probably has relatively low prestige.

We can say that for a minoritised language to be revitalised, three conditions must be met: people must be capable of using it, having learnt it in the home or through minority language education, they must have the opportunity to speak it, in both private and public lives, and they must have the desire to use it. All of these three conditions are interrelated with the positive attitudes towards the language. To be able to achieve these conditions, there must be a strong language policy with top-down language support. For example, there must be: opportunities to learn the language; the existence of a language infrastructure with support for families who want to bring up their children in the minority language; and job opportunities in the minority language and possibly other economic profits to increase people's motivation to learn it and use it. Furthermore, the role of media must not be underestimated. Both the language and the speech community must have a positive image in wider society. It is also important, especially for the younger generation, that the use of a language is not uniquely linked with the past and tradition, but also with what is perceived as 'modern' and 'cool'. Therefore, for people to have positive attitudes towards a language, it should be used in all domains of their daily life, from the family domain, to school, work, and social media.

\section{Positive Attitudes towards Multilingualism}

Once intergenerational transmission of the language has been interrupted or broken it is important to take into consideration not only the language attitudes of active speakers, but also the attitudes of those who do not speak it. A contemporary minority language community may include native speakers (who may or may not choose to use the language), people who have learned the language of the minority and use it, and those who are indifferent or have negative attitudes towards it. Moreover, there are 
individuals who are considered members of the speech community and are surrounded by and/or mix with those who do not identify themselves with any particular group, but may be interested in learning and using the language. The 'speech community' may therefore also include 'potential speakers', who should also be targeted by revitalisation activities.

Therefore, promoting positive attitudes towards multilingualism becomes one of the main aims of revitalisation efforts, allowing new speakers of an endangered language to become part of the community. In this regard, an education system, which is open to both native and non-native speakers, can play an important role. There should be a place where children can learn the language and, preferably, also learn through the medium of this language. The latter is important for changing language ideologies that claim that it is not possible to express everything in the minority language, or that learning in this language causes harm to children. Moreover these educational settings should be of the best quality in order to encourage parents to send their children there. One possible solution is to provide teaching in three languages: the minority language, the dominant/state language, and English (as a global lingua franca). Another possibility is to work with institutions and social media to raise awareness of the benefits of multilingualism. For example, multilingualism raises cognitive abilities and creativity. Moreover, children who speak at least two languages have higher language skills; find it easier to solve problems; to distinguish meaning from form; to listen and remember; and to learn any additional language faster. ${ }^{4}$ These benefits can increase the child's chances of obtaining a good job in the future and can help them to cooperate effectively with other people. These arguments are based on the intellectual advantages of learning a minority language rather than the emotional, identity-based, benefits. This reasoning may help to create more new speakers and to convince parents from the speech community that it is good for their children to learn and use their heritage language.

\section{Conclusion}

Language ideologies which operate at a sub-conscious level express themselves in peoples' attitudes, opinions, and beliefs towards a given language or language variety. Both language ideologies and language attitudes are very important to the revitalisation process. Therefore the first step when planning new revitalisation strategies should be an examination of the

${ }^{4}$ For a summary of research on such benefits, see E. Bialystok, F. I. M. Craik, and G. Luk, 'Bilingualism: Consequences for mind and brain', Trends in Cognitive Sciences 16(2012), 240-50. 
existing language ideologies and language attitudes in a given society or community. Without this knowledge, revitalisation efforts could fail. Recognising language ideologies, such as the ideology of the standard language, of authenticity and ownership, is the first step in overcoming them. The same concerns language attitudes. There is a need to understand attitudes towards the minority language in both the minority speech community members and wider society.

Changing language ideologies, whose power lies in the fact that they are innocuously and deeply imprinted in people's brains, is a long-term process. The best method to do so is to make people aware of their existence and how they function.

Formal and informal education can be helpful here. One of the primary goals of any revitalisation program is to activate speakerhood and to produce more speakers of an endangered language. Part of this process should consist of familiarising people with the fact that language ideologies are socially constructed and that they can be changed. Informal education also plays a vital role in producing positive attitudes towards the language and motivating people to use it. For example, creating different events and activities for speakers and people who are learning a language to meet can actively encourage them to use the endangered language, even if it is difficult for them. This can also contribute to building a common language identity amongst speakers and creating positive attitudes towards the language.

Media has the power to create a positive image of both the endangered language and the speech community (including native and new speakers). When a language that is otherwise considered 'not useful' or 'backwards' is presented in the media, online, or in computer games, it can appear modern and attractive, particularly to young people. Another role of the media is to create a positive image of the speech community, minimising their reluctance to use their language in public life. When a speech community is presented as being full of life, new ideas, and resistance, this may also contribute to changing language ideologies and attitudes and, as a result, language practices.

To change language ideologies and attitudes, it is also helpful to strengthen the presence of the endangered language in the linguistic landscape. Bilingual inscriptions signal a collective identity, as well as equality between the endangered language and the dominant language. The presence of an endangered language in the written form augments its prestige and social significance, thus breaking the symbolic domination of the majority group. Numerous studies on 'linguistic landscaping' have demonstrated how minority language spaces are symbolically defined through the medium of writing, particularly on street signs, billboards, 
and signs in public buildings, etc. However we should also bear in mind that some languages have more of an oral presence, and that they are more likely to be heard rather than seen in written form. In these cases, the media can also be used to create a 'soundscape', for example, through public announcements in train stations and airports and the availability of radio and TV shows in the minority language, etc. These are important considerations when engaging in language revitalisation planning.

To conclude, when speakers' and community members' language ideologies and attitudes are negative, this could jeopardise revitalisation efforts. In order to prevent this, a community should identify existing ideologies and their roots. This will help in understanding language attitudes within the community. We should establish programs aimed at diminishing the impact of negative language ideologies (for example, through community campaigns and activities) and reinforcing positive language attitudes with the use of social movements, cultural activities, supportive language policy, the linguistic landscape, and last but not the least, formal and informal education.

\section{FURTHER READING}

Baker, C. (1992). Attitudes and Language. Clevedon: Multilingual Matters.

Blommaert, J., ed. (1999). Language Ideological Debates: Language, Power, and Social Process 2. Berlin: Mouton de Gruyter.

Gal, S. and Woolard, K. A., eds. (2001). Languages and Publics: The Making of Authority. Manchester: St. Jerome.

Garrett, P. (2010). Attitudes to Language. Cambridge: Cambridge University Press.

Garrett, P., Coupland, N., and Williams, A. (2003). Investigating Language Attitudes: Social Meanings of Dialect, Ethnicity, and Performance. Cardiff: University of Wales Press.

Schieffelin, B. B., Woolard, K. A., and Kroskrity, P. V., eds. (1998). Language Ideologies: Practice and Theory. Oxford studies in anthropological linguistics 16. New York: Oxford University Press.

Woolard, K. A. (1998). Introduction: Language ideology as a field of inquiry. In B. B. Schieffelin, K. A. Woolard, and P. V. Kroskrity, eds., Language Ideologies: Practice and Theory. Oxford: Oxford University Press, pp. 3-47.

\subsection{Language Ideologies in an Endangered Language Context: A Case Study from Zadar Arbanasi in Croatia Klara Bilić Meštrić and Lucija Šimičić}

Language ideologies can be defined as socially, historically, and politically shaped ideas about language, which often have far-reaching and irreversible effects on language attitudes and linguistic practices. This is the case in the context of Arbanasi, a language spoken by approximately three hundred, mostly elderly, 
people in the city of Zadar, Croatia. The language has been classified as highly endangered by UNESCO. Based on the Gheg dialect of Albanian spoken by Catholics fleeing the Ottoman wars in the early 1700s, Arbanasi underwent significant linguistic influence from Venetian, Italian, and Croatian, especially in its vocabulary. Today it is not institutionally protected as, among other reasons, its speakers do not claim a separate national minority status. Furthermore, having been classified as intangible cultural heritage in Croatia along with around twenty other minority languages and language variants grants its speakers only symbolic recognition.

The ideologies behind the loss of Arbanasi reflect several highly interrelated features, which are all related to the devalued role that many minority languages have in society. The pervasive attitude among Arbanasi speakers and the wider community that Arbanasi is not a proper language is due to: (a) a high level of 'mixing' with other languages, (b) a high degree of variability in both grammar and vocabulary, (c) a lack of written tradition accompanied by the absence of standardisation. Such attitudes are based on the ideology that languages are abstract, stable, pure, countable entities with clearly defined borders; at the same time, this belief sees all other language varieties as less valuable. However, this view often ignores the fact that languages are always a form of social reality and that the selection of a language norm is usually historically and politically motivated. Proponents of this ideology question the idea that languages marked by a high level of 'mixing' and/or variability can be perceived as fully legitimate. Consequently many Arbanasi speakers are reluctant to call Arbanasi 'a language', and prefer to refer to it as 'a dialect' or 'a speech'. For others, however, it is precisely this linguistic hybridity, that is the fact that it is so highly interspersed with Croatian and Italian (Venetian) influence, which functions as a source of pride and leads them to refer to it as a language in its own right; one that is different from modern standard Albanian (based on the Tosc variety).

Since languages proper are often equated with standardised and written varieties, many believe that Arbanasi, not having been written down, cannot be accorded the same rights as developed national languages. However the desire to prescribe written norms for Arbanasi is only marginally present in the community since not everyone considers it necessary for language learning, and much less so for (occasional) informal texting and similar. A recent attempt to write down Arbanasi using the Croatian writing system also caused heated discussions since many believe that the traditional Albanian-based writing system is more 'correct' and more likely to grant Arbanasi a legitimate 'language' status.

At a more personal level, linguistic insecurity is visible in Arbanasi as speakers become increasingly aware of language decline manifested mostly in numerous lexical gaps, with words missing even for everyday concepts. Moreover, due to reduced language productivity to create new words in Arbanasi, it is the lexical level that serves as an ideological battlefield; by endorsing either the modern Albanian standard variety (Tosc) or Croatian, (groups of) community members promote their view of a 'correct' language. Moreover occasional instances of insisting that there is an original, genuine version of Arbanasi that some, mostly 
senior speakers, use, only increase the reluctance of many Arbanasi to speak their language. Such a feeling is especially pronounced among those who tend to codeswitch a lot and/or insert Croatian and (to a lesser extent) Italian lexical borrowings into their speech. At the same time, the myth that speaking Arbanasi at home will cause its young speakers to make mistakes in Croatian has contributed to the interruption of intergenerational language transmission in many families. This reflects an ideology of monolingualism, which is usually based on the fear that an official, national, or a language of a majority cannot be properly mastered if the traditional language is still in use.

Today, the youngest known speaker is in his early thirties and, to our knowledge, the language is not being transmitted in families (there are no children who are growing up with Arbanasi). There are a few places where the language can be heard in public and one of them is a language course in the city library. This course is a community-based initiative, where mostly traditional and latent speakers gather because it is the only chance for them to use the language. It is also an arena where the different aforementioned ideologies often come into play. Bearing in mind the decisive role that language ideologies and attitudes play in language shift in the Arbanasi context, it is clear that addressing language ideologies at the grassroots level should therefore be the starting point in any revitalisation effort.

\subsection{Attitudes towards Guernesiais}

\section{Julia Sallabank}

Guernesiais is the Indigenous language of Guernsey, Channel Islands (between Britain and France). Traditionally Guernesiais was seen as a 'poor relation' of French. French was used in the government, the judiciary, religion, and education, while Guernesiais was used between family and friends. Although the Channel Islands have been associated with Britain since the eleventh century, it is only since the nineteenth century that English has become widespread. English spread quickly (especially once radio brought it into homes) and it is now the dominant language, while Guernesiais has only a couple of hundred speakers: most fluent speakers are aged eighty or over, and there are very few speakers below the age of sixty.

One commonly expressed attitude towards Guernesiais is that it is 'not a proper language' but either a dialect of French or a mixture of English and French. In response, language supporters point out that Guernesiais is a variety of Norman, which has a prestigious history - reclaiming prestige is an important principle.

Until the late twentieth century, even in areas where the language was spoken most widely, people assumed that if children learnt Guernesiais they 'would never know English'. One woman remembered how in the 1950s neighbours told her mother that 'when she goes to school she won't be able to learn' if they spoke Guernesiais (she is now an accomplished musician).

By the early twenty-first century, however, it became clear from media reports and anecdotes that attitudes towards Guernesiais were becoming more and more positive. Speakers started to express pride: 'In certain company you didn't speak 
it - because it made you feel a bit inferior but now it's the other way round - you don't feel at all inferior if you know it, it's completely the opposite you know?'

I conducted a representative survey in $2004^{5}$ and found overall strength of support for Guernesiais even higher than anticipated: for example, 50.5 per cent disagreed strongly and 25.3 per cent mildly with the statements, 'It doesn't matter if Guernesiais dies out' and 'Guernesiais is irrelevant to the modern world'. Attitudes towards bi/multilingualism were also much more positive. Although these results were the same across gender, job sector, and geographical origin, as well as proficiency in Guernesiais, people with higher levels of education had marginally more positive attitudes. When the results were analysed by age group, under- $18 \mathrm{~s}$ were found to be slightly more likely to have negative attitudes. Although the difference was minimal, the attitudes of young people are of course key to a language's future. However several interviewees commented that it is common to reject traditional values in your teens and twenties, but some become enthusiastic about Guernesiais in middle age or later.

This survey included not only Guernesiais speakers but reflected the general population in that only 2 per cent speak the language, and 36 per cent were born outside the island. A crucial factor in this apparent majority-population support for a minority language may be that many of the majority population see Guernesiais as part of their heritage too, not only that of the dwindling number of native speakers; this is even true of respondents who are not of local origin.

On the face of it, such majority support would appear to bode well for the future of the language. Yet not all older speakers have fully accepted a higher status for Guernesiais - some still unconsciously perceive Guernesiais as lacking in prestige. In addition, there is an influential minority who cherish Guernesiais as the language of their youth, and who seem unwilling to hand over control to a new generation or to new speakers. It is often assumed that young people and immigrants will not be interested in Guernesiais, and language maintenance activities can perpetuate this stereotype by focusing on traditional culture. Language activities need to be inclusive to attract people of all ages and backgrounds. It should be remembered, however, that attitudes are not actions: positive attitudes cannot save a language without concrete measures. However, they can lead to public support and funding for such measures.

\subsection{What's the Point of Manx?}

\section{Adrian Cain}

Manx is a Celtic language spoken in the Isle of Man/ Ellan Vannin, an island in the Irish Sea mid-way between Wales, Scotland, and Ireland. The last traditional native speakers died in the 1970s; at that point one might have asked 'What's the point of Manx?' Indeed Manx was categorised as 'extinct' in 2009 in the UNESCO Atlas of

5 See J. Sallabank, 'Can majority support save an endangered language? A case study of language attitudes in Guernsey'. Journal of Multilingual and Multicultural Development 34/4 (2013): $332-47$. 


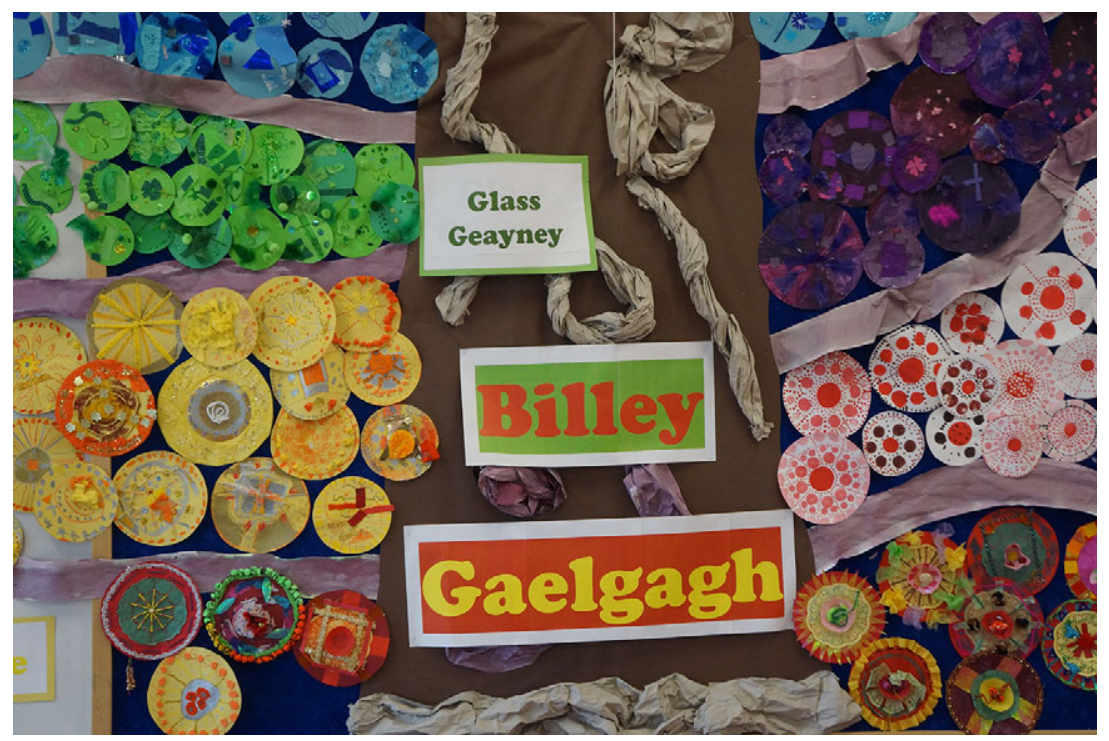

Figure 7.3.1 Language materials in Manx. Photo by Justyna Olko

Languages in Danger. But Manx is actively used through revitalisation efforts such as adult lessons, Manx music sessions, preschools, a Manx walking club, bilingual signage, radio broadcasts, conversation groups, and optional lessons in mainstream schools. There is a Manx-medium primary school which teaches all subjects through Manx, with seventy pupils (see Figures 7.3.1 and 7.3.2). According to the 2011 Census there are over 1,800 speakers.

I don't get asked the question 'what's the point of Manx Gaelic' too often these days and that probably reflects a change in attitudes towards the language; however, if I do, my usual response is, 'What's the point of the Isle of Man?'

Having lived in London for a number of years I'm aware that most people outside of the Island have a very poor understanding of the Isle of Man, which at best consist of a series of clichés such as 'tax haven', 'TT races', and 'cats without tails'. Unfortunately many such clichés are peddled by the supposedly liberal press in London too.

In this sense, the revitalisation of the language here is as much about changing perceptions towards the Island as it is about getting people speaking the language. Moreover, if the Island is to rid itself of these misconceptions and lazy journalism, it needs to be telling a different narrative about itself, its history, and its culture: the revitalisation of the language in this sense is a positive news story about the Island that tells a different narrative. We are more than just a wellregulated 'off-shore' tax jurisdiction, but an Island entitled to our independence which has a positive story to tell the rest of the world about language revitalisation and identity. 


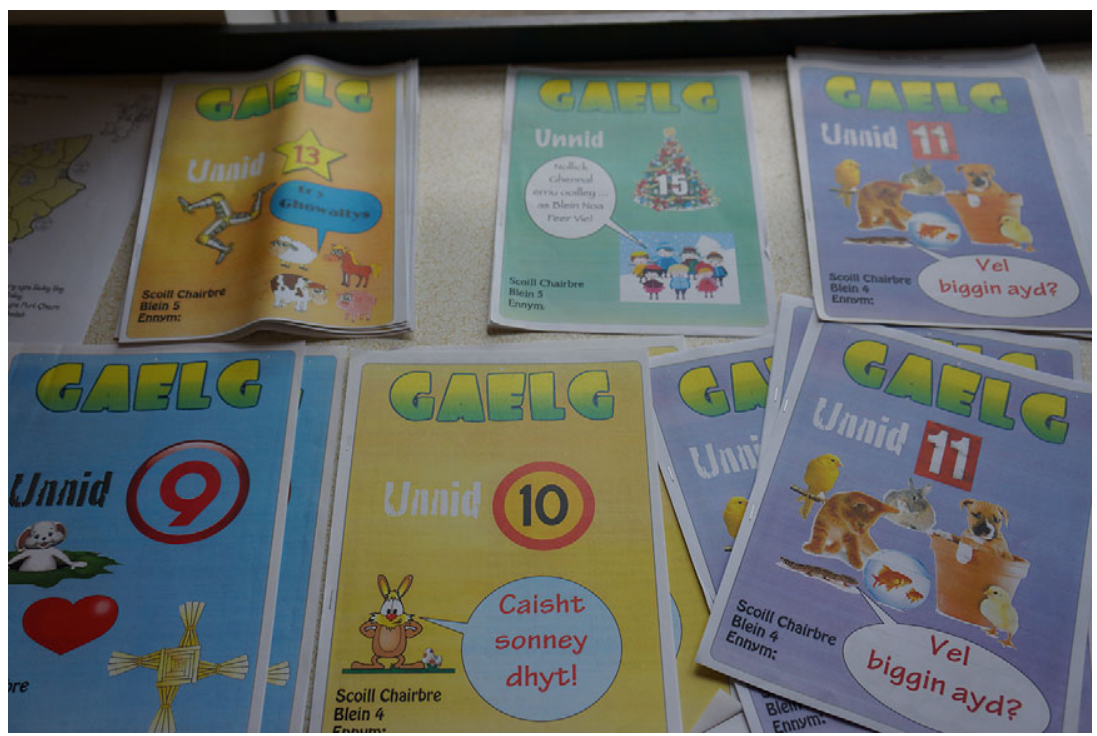

Figure 7.3.2 Manx for children. Photo by Justyna Olko

A follow-up question might indeed be 'who are the Manx?' these days. The Island has changed fundamentally from that of the last native speakers. Much of the change, but not all, has been good and the reality is that less than half of our community now were born here. 'What is the language to them?' Ironically, the language is one of the few things that the last native speakers would recognise about the Island, but if the language is to mean anything these days it needs to be seen as a language of modernity - associated more with the Internet than thatched houses and fishermen. This Island is open to anyone who wants to make it their home (it doesn't matter if you were born in Portsmouth, Port Moresby, or Port Elizabeth). What's more, the language and the culture that accompany it can belong to you as much as they belong to someone from a long line of Manx descendants who was born and brought up on the Island.

The Island has changed and will continue to do so; however, the language and culture are stronger than they have been for over 100 years. Although the future will be challenging, there is a growing acceptance from politicians and business people on the Island that the language and culture tell a different narrative for our Island; that is, that the language is forward looking and welcoming to new learners and speakers of different backgrounds.

What languages need, therefore, is a vision: a sense of what has gone and what is possible. But this vision needs to avoid arguments about how authentic modern Manx is, and offer instead a sense of what our languages can be in a rapidly changing world.

'What is the point of the Isle of Man?' Therein lies the future of our language. 


\section{FURTHER READING}

Clague, M. (2009). Manx language revitalization and immersion education. e-Keltoi: Journal of Interdisciplinary Celtic Studies, 2, Article 5. https://dc.uwm.edu/ ekeltoi/vol2/iss $1 / 5$.

Manx: Bringing a language back from the dead, www.bbc.com/news/magazine21242667.

Manx Language Network - Your one-stop shop for all things Manx Gaelic: Learn, use and support Manx, www.learnmanx.com.

How the Manx language came back from the dead, www.theguardian.com/education/ 2015/apr/02/how-manx-language-came-back-from-dead-isle-of-man.

\subsection{Emotions and Relationships in Language Revitalisation and Maintenance ${ }^{6}$}

\section{Soung-U Kim}

While working on Jeju Island, South Korea, I had the opportunity to speak to people about what their local language variety 제주돗말, Jejudommal (pro-

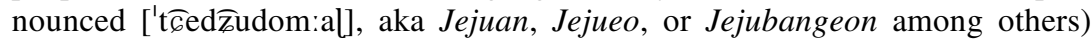
means to them, as opposed to the national language, Standard (South) Korean. Transmission of the speech of the oldest generation has ceased, yet a number of traces remain in the way the youngest generation speaks. Younger people may consider themselves speakers of Jejuan nonetheless, and as much as 'Jejudommal' and 'Standard Korean' do exist in speaker's minds as entities, so are emotional meanings constructed and assigned to these different ways of speaking. That is, ideological connections with the emotional meanings of language use may even persist in cases when there is no intergenerational transmission.

Jejudommal is regarded as having much richer words to express sounds, feelings, moods, and attitudes, whereas Standard Korean is seen as sounding more 'sober', with more clearly definable words. Still, people's impressions go well beyond language: Speaking Jejudommal is often considered more appropriate in a relaxed, trusting, and intimate atmosphere where emotions may be expressed freely, and where people feel much more connected to their emotional lives themselves (e.g. when talking to close relatives or friends). Contrastingly people associate speaking Standard Korean with having to keep themselves in check, and with leading rational conversations, which purely serve the purpose of communicating 'cold' information between people who have to maintain a particular distance. Naturally people often say that they feel more disconnected from their own feelings and expressing them in such situations - a classic example is that of a work meeting.

${ }^{6}$ This work was supported by the Laboratory Program for Korean Studies through the Ministry of Education of the Republic of Korea and Korean Studies Promotion Service of the Academy of Korean Studies (AKS-2016-LAB-2250003). 
Isn't this interesting? When we talk about language revitalisation and maintenance, our attention is often directed towards more 'objective', 'tangible' things, for example, domains of usage, language materials, education, speaker numbers, and such. Rarely, however, do we talk about the emotional meanings and values that we attribute to the languages that we speak, and also the emotions that our very language choices evoke. Maybe it's because emotionality is stereotypically considered vague and difficult to measure, or maybe thinking and talking about our emotions may not be considered the most 'professional' approach in our revitalisation 'work'.

What we are trying to achieve here goes way beyond a task where we merely repair a dysfunctional machine; rather we are working towards a profound transformation of deeply ingrained habits - our everyday language choices - which are connected to a much wider web of being human. If that is the case, in language revitalisation we should take into account something that is crucial to us as human beings: our emotional lives, and how they relate to the language choices we make.

Thus it may be worthwhile reflecting on what feelings, thoughts, values, and images you associate with speaking your minority language(s), compared to the dominant language(s) of the majority. How does it make you feel when you speak or hear 'your language'? Which language variety do you choose in particular situations (certain people in your family, at work, at school, with friends, in a shop, etc.), and why? How would it make you and others feel if you chose to speak a different language from what people are used to in those situations? Feel free to ask your family and friends and many others - the goal is to see what emotional values and meanings are shared between members of your community to use that knowledge productively for language revitalisation work.

Taking on such a perspective may in fact inspire your language revitalisation practice and planning: what if you tried to go about strengthening language use not only by tackling certain domains, but also, with respect to strengthening particular spaces and relationships that appeal to people's emotions? Similarly how about reflecting on the emotional relationships you forge on a daily basis through your language? Can you help to foster positive emotions connected to the use of your language? Of course, one should not dismiss the insights of language revitalisation studies so far, but I do think that we must acknowledge that we are more than just 'brains with limbs and organs' exchanging facts through speech, and that language revitalisation, therefore, must be about more than language. Essentially it's about being human, together - or in the worst case, alone.

\subsection{Nahuatl Language Ideologies and Attitudes}

\section{Justyna Olko}

Today Nahuatl is still spoken in several Mexican states, in both rural and urbanised settings (although much less frequently in urban centres). The Mexican National Institute of Statistics and Geography (INEGI) reported in 2010 an official population of as many as 1,544,968 native speakers of the language. Nonetheless, in most Nahua communities intergenerational language transmission has drastically been 
weakened or has broken down entirely over the last few decades. This was accelerated, and in many cases directly provoked, by a pervasive ideology of racism, as well as by school policies. Indigenous children were subject to many forms of violence and discrimination at school, and negative ideologies were internalised by community members. Today such community-driven racist attitudes are remembered by children raised in the 1980s, such as a community member from Tlaxcalancingo in Puebla raised monolingually in Nahuatl by his mother, with whom I spoke in 2014. It took him a long time to learn the dominant tongue well and he was an object of prolonged mockery and humiliation by his peers: 'Everybody was saying that it sounded funny or that I made them laugh. [I only knew how to say] "Good bye" and "give me permission to go to the toilet." All my friends with whom we studied were laughing [at me]. I was taking a long time to learn well [Spanish]. They were insulting me, mocking me, [saying] I was an indio, stinker, that [I] bathe myself in a steam bath, that I carry a spittle of cactus and saying other things'.

The heritage language is seen as the most visible sign of the previous, 'uncivilised' state of existence, associated with backwardness, positioning indios, a derogatory term for Indigenous people that goes back to the early colonial period, as the lowest, most disadvantaged, and backward social group. As remarked by one of the few remaining elderly speakers in the community of San Pedro Tlalcuapan in Tlaxcala in 2017, 'Because they [community members] are ashamed, they do not want [to speak], they tell as we are indios, one who speaks Nahuatl is an indio'.

When Nahua people from more isolated (especially mountainous) communities come to nearby urban centres to sell their goods to earn a basic living, or when Indigenous children commute to regional schools, they often experience abuse and discrimination. Language and ways of dressing are perhaps the most obvious identification markers, so they take efforts to hide their ethnic characteristics in order to avoid mistreatment. This discrimination is experienced by members of marginalised Nahua-speaking communities, and is carried out by residents of more 'modernised' Nahua towns. A woman from a little village in the Sierra Norte de Puebla, who married into a central Tlaxcalan community and has been living there for twenty years, testified that she was mocked and discriminated against because of her origin, even by members of her new family who are themselves speakers of Nahuatl.

As pointed out by a community member from the Contla region in Tlaxcala, people feel 'denigrated' and 'ashamed' to speak Nahuatl, while the few conversations in this language are limited to the themes of agriculture and communication with workers who often come from more mountainous communities: 'We barely communicate in Nahuatl. We speak Nahuatl very rarely with my wife and kids. Sometimes we speak Nahuatl when we talk about farming and the field, when we talk with the workers. We can have a conversation with the people we meet [on the street] if they do not feel ashamed, but there are people who feel very ashamed. One denigrates himself for speaking Nahuatl. Sometimes we speak Nahuatl with the people from the sierra (mountainous regions) who speak Nahuatl, but when it is just us here, well, we don't'.

${ }^{7}$ Interview recorded by Aleksandra Bergier in San Miguel Xaltipan, Contla, Tlaxcala. 
Thus, members of native communities situate Nahuatl at the very bottom of the language hierarchy. Spanish is in the middle as a national language and that of the dominant 'modern' society. Most recently, English has taken the place at the very top as a symbol of upward social mobility and opportunities. It is associated with technology, business, youth, and popular culture. For members of a community with high rates of migration to the USA, it is also the language of remote opportunities and a symbol of a better life. Spanish, in turn, is linked to all basic aspects of social life, as the sole language of education, politics, work, legal, and public services. When compared with these two languages, Nahuatl's domains are limited to the household, family, and agriculture, as a lower-status tongue of campesinos (peasants). These attitudes are closely linked to a deep denial of the reasons for language shift, especially in the generation of speakers who decided not to speak Nahuatl to their children. Community members remain largely silent about the reasons and circumstances of what occurred. Some spoke some Nahuatl to their children or speak it occasionally to the grandchildren, but they say the failure is on the part of children and grandchildren who refuse to speak the heritage language. Some elder speakers deny anything really happened: they declare there was no pressure or discrimination, just everybody in the neighbourhood started to speak Spanish. This erasure of recent and painful experiences fits well into a widely shared image of modernisation and peaceful transition for a 'better status'.

Children who acquire their heritage tongue at home usually learn at school and/ or in the community that it has no value. They often choose to pursue a path to a higher social position than their parents by learning English. Most of them will never go back to speaking the mother tongue. But exceptions and new role models are possible. These are the words of a young and successful engineer from a Nahuatl-speaking family in San Miguel Tenango, Puebla, who decided to invest in his skills in Nahuatl and started to promote it in his home community among the younger generation:

'And at school they say that if you want to find a good job, teach yourself to speak English. So I started studying English. When I started, I said to myself one day, "This English is indeed difficult." Then I said to myself, "So I am learning to speak English, and what about Nahuatl? I also know how to say [something], and I only do not know how to write it. I do not know how to write it, but I know how it sounds." And I said, "So, if I have studied to speak English, I should also teach myself to write and to speak my language well".' (San Miguel Tenango, Zacatlan, Puebla, 2015) 